\title{
THEORIES OF SUBSTANCE ABUSE PREVENTION IN THE WORKPLACE
}

\section{Wilhelmina Steenkamp}

\section{INTRODUCTION}

Workplaces have been identified as important structures for the implementation of alcohol abuse prevention programmes (Ames, 1993; Cook \& Youngblood, 1990; Gill, 1994; Heirich \& Sieck, 2000; Parry \& Bennets, 1998; Roman, 1990; Roman \& Blum, 2002; Snow, Swan \& Wilton, 2002). The need for substance abuse prevention programmes in the workplace has also been recognised by South African authors (Albertyn \& McCann, 1993; Parry \& Bennetts, 1998; Strydom, 1997). The National Drug Master Plan: 2006-2011 (Department of Social Development, 1997), which directs all substance abuse services in South Africa, has prevention amongst workers as one of its priority areas.

Evaluations of existing workplace-based programmes, however, have not reported much success (Ames, 1993; Holder, 1998). Moskowitz (1989:75) remarked: "Whereas many have argued for the conceptual and practical advantages of workplace prevention programs, there is an absence of both viable program models and research data to support the efficacy of this approach for preventing alcohol problems".

It is the opinion of the author that one of the contributing factors to the poor performance of workplace-based prevention programmes can be found in the conceptualisation and design of the programmes. All social programmes are based on a theory of how the intended programme will address an identified need. This means that when a programme is implemented, programme planners have an idea of how and why the efforts will address a need or lead to a change that is in the interests of the programme beneficiaries. The theory may be implicit or may be well defined. Chen (1990:39) remarks: "The question of how to structure the organized efforts appropriately and why the organized efforts lead to the desired outcomes imply that the program operates under some theory. Although this theory is frequently implicit or unsystematic, it provides general guidance for the formation of the program and explains how the program is supposed to work". In an educational alcohol abuse prevention programme, for example, the theory is probably that information on the consequences of alcohol abuse improves the knowledge of the target group; improved knowledge leads to attitude change and the change in attitude leads to behaviour change. Programme theory is constructed from the view of role players and from social science theories. However, the programme theory may be weak or wrong, especially if it is not based on scientific evidence. The experience of the author is that in South Africa many prevention programmes are implemented that are not based on scientific evidence, as described in social science theory. The reason why a programme is implemented can more often be found in customary practice than in clear thinking about theories of change and evidence-based practice.

The aim of this article is thus to discuss theoretical approaches to the prevention of alcohol abuse. Programme planners can use the information to design prevention programmes that are based on a sound programme theory, constructed from the social science theory described here. Ultimately the aim is to contribute to more viable and successful programmes and evidencebased practice. The traditional approach, the ecological approach, the health promotion approach and the coping skills approach will be discussed. 


\section{THE TRADITIONAL APPROACH}

Traditionally alcohol problems in the workplace have been managed by employee assistance programmes, the formulation of a substance abuse policy, training of supervisors and managers, information sessions for employees and chemical testing for substances (Cook \& Youngblood, 1990; Cook, Back \& Trudeau, 1996a; Gill, 1994; Trice \& Sonnenstuhl, 1990). According to the South African literature (Albertyn \& McCann, 1993; Parry \& Bennetts, 1998; Strydom, 1997), this approach was the one followed almost exclusively in South Africa.

\section{DESCRIPTION OF THE TRADITIONAL APPROACH}

Employee assistance programmes (EAPs) focus on the identification of employees with alcohol problems, assessment of the problem and referral to inpatient or outpatient treatment centres. Employee assistance programmes can be considered as tertiary prevention or treatment. Some authors (Roman \& Blum, 1996; Strydom, 1997) see this type of services as secondary prevention, as the emphasis is on early identification and treatment. Intervention is offered before the employee loses his job and before the stage of chronic dependence is reached. Early diagnosis also means that the prognosis of treatment is better.

Employees with alcohol problems are often identified by their supervisors and referred to the EAP. Employees are identified on the grounds of their under-achievement in the workplace. This typically includes absenteeism (especially after a weekend or after pay day), increase in the use of sick leave, increase in workplace accidents, conflict with colleagues and reduced productivity. Supervisors are trained to identify the problem worker, confront the worker constructively and refer them to the EAP.

Employees can also approach the EAP on their own initiative or can be referred by family, colleagues or unions. Often disciplinary committees refer employees if it becomes evident, during the hearing, that alcohol problems contribute to the problem.

Often treatment consists of inpatient treatment. Alcohol dependence is seen as a complex problem and a multidisciplinary approach is followed. The aim of the treatment is abstinence and an alcohol-free lifestyle. Controlled alcohol use or responsible use is normally not an aim of this type of programme.

As part of the traditional approach, a substance abuse policy is drawn up. This is done in collaboration with stakeholders, e.g. management and the unions. The substance abuse policy normally specifies:

- the organisation's views on the use and abuse of substances;

- rules regarding the use of substances at the workplace;

- the disciplinary procedure that will be followed where the rules are transgressed;

- provision for treatment and procedures for referral for treatment;

- the preventative and educational programmes that the workplace provides.

In some organisations the substance abuse policy makes provision for testing of employees for the presence of substances in the system. Testing might be done prior to employment, or occasionally, e.g. after an accident or at random, according to the decision of the employer. Testing can contribute to the reduction of substance abuse at the workplace, but is not effective for the treatment or prevention of substance abuse.

Educational methods are used for primary prevention. The aim is to educate the workforce about the negative consequences of alcohol abuse. Employees are educated about the fact that: 
- alcohol is addictive;

- alcohol abuse has personal, physiological, social and psychological consequences;

- addiction is a process that often starts with "innocent" social drinking;

- alcohol abuse is a common and extensive problem;

- help is available.

In addition to the education of the workforce, the management, supervisors and representatives of the unions are also trained. Training of management includes the raising of awareness about the influence of alcohol abuse on productivity, and the social responsibility of management towards employees. The programme is marketed to management in this way. Supervisor training is an important element of the programme and focuses on skills related to the identification of alcohol abuse problems, the confrontation of the employee and referral to the EAP.

The underlying theory in the traditional approach is that more knowledge will lead to attitude change and a change in attitude will lead to a change in behaviour. However, Pentz (1999) maintains that programmes that are didactic in nature and focus only on the acquisition of knowledge about substances and the consequences of abuse have no effect. The traditional approach also focuses predominantly on treatment and hence prevention plays a minor role in them.

\section{EXAMPLES OF PROGRAMMES THAT FOLLOW A TRADITIONAL APPROACH}

There is some support in the literature for programmes that implement at least three of the elements of the traditional approach, namely the formulation of the substance abuse policy, the EAP programme and education (Trice, 1990).

Roman and Blum (1996) did a literature study on the efficacy of alcohol abuse treatment at the workplace. Twenty-four studies matched the inclusion criteria. Twenty-one of these studies were based on an EAP model of treatment. Three studies were educational in nature and focused on the training of employees, supervisors and management. The effect of the intervention was determined by the following factors:

- Changes in knowledge and attitudes regarding drinking practices;

- Changes in willingness to refer employees for intervention;

- Decrease in amount of alcohol consumed or in unhealthy drinking practices;

- Changes in work behaviour, e.g. better productivity and less absenteeism.

The authors came to the conclusion that most studies demonstrated positive results, although there were methodological problems: "The literature therefore demonstrates the generalized efficacy of interventions that are fashioned after the EAP model in dealing with employee alcohol problems and the value of training and education in changing attitudes, behaviour, and EAP utilization" (Roman \& Blum, 1996:146). However, as has already been said, most of these studies focus on treatment and not on prevention.

Of the three studies in the Roman and Blum (1996) analysis that can be described as preventative, two follow a life skills approach and a healthy lifestyle approach respectively. The study by McLatchie, Grey, Johns and Lomp (1981) can be described as an educational prevention programme. In the latter study the programme was presented to two groups of employees in a manufacturing enterprise in Ontario. A group of 61 employees consisted of supervisors, section managers and union representatives. The other group consisted of 142 
hourly-paid employees. A 30-minute session was presented to the hourly-paid employees. The group with the supervisors attended a session of one and a half hours. Both groups received information on alcohol abuse, the policy of the organisation and treatment facilities. The supervisor group received additional information on the role of supervisors, managers and union representatives. Audiovisual material, group discussions and short lectures were used in presenting the material. A questionnaire was administered before and after the intervention to test knowledge about alcohol, knowledge about the policy of the organisation and willingness to accept treatment. There was no control group. The results were that both groups increased their knowledge about alcohol and about the policy of the organisation, and that the hourly-paid workers were more willing to accept treatment. The study did not test the effect on the consumption of alcohol.

Cyster and McEwen (1987) also described an educational programme that was presented in the British Post Office. The aim of the project was to:

- improve knowledge on the nature and effect of alcohol abuse;

- introduce the policy of the Post Office on alcohol abuse;

- encourage positive attitudes towards responsible alcohol use.

The information was presented by means of a video-tape. The person presenting the video was also available to answer questions. In addition, employees could play a computer game that was aimed at improving knowledge about alcohol. The video was presented to groups of 25 to 30 employees. The presentation took 30 minutes. Training of supervisors was another aspect of the programme. Questionnaires were again distributed before and after the intervention. There were no control groups. The results were that there was a small increase in knowledge, but no change in attitude towards drinking, social pressure to use alcohol, or alcohol use.

The programmes discussed in this section confirm the general conclusion that educational prevention programmes can lead to an increase in knowledge, but do little to change drinking behaviour. There is also an over emphasis on treatment in the traditional approach, to the detriment of prevention.

\section{THE ECOLOGICAL APPROACH}

The main proponent of the ecological approach is Genevieve Ames (Ames, 1993; Ames, Grube \& Moore, 1997; Ames \& Grube, 1999; Ames \& Janes, 1990; Delaney \& Ames, 1995).

\section{DESCRIPTION OF THE ECOLOGICAL APPROACH}

Ames questions the general tendency to ascribe the causes of alcohol problems to individual characteristics only. She focuses instead on social and cultural factors in the workplace that contribute to alcohol abuse. Factors that have been identified are:

- control (policy, rules, visibility of work and efficient supervision);

- physical and social availability of alcohol (can alcohol be obtained at the workplace and is alcohol use accepted by co-workers);

- quality of work (stress, physically demanding work, exclusion from decision making, unrealistic expectations and job insecurity).

Several studies were done to determine the relationship between these factors and alcohol problems in the workplace. Ames and Janes (1990) found that the workplace can sustain heavy drinking. A study amongst 6000 employees whose services were terminated revealed that most workers drank less after the termination, although their salaries remained constant because of 
insurance. Delaney and Ames (1995) found that positive attitudes towards work groups led to more positive norms regarding drinking. Positive norms resulted in less alcohol use. Ames and Grube (1997) found that employees' conceptions about the drinking practices of colleagues were the most important factor in determining their own drinking patterns. Seeman, Seeman and Budros (1988) did a study on alienation and alcohol abuse. They found that a feeling of helplessness was directly related to alcohol abuse.

Trice and Sonnenstuhl (1990) developed a classification of factors that contribute to workplace drinking.

- The cultural perspective refers to norms and attitudes about alcohol use that develop in a particular work setting. In some professions, e.g. the military, alcohol use plays an important role in the workplace culture.

- The social control perspective refers to those factors that impede the worker's integration into the workplace, e.g. a lack of supervision, low visibility of the worker (as in travelling jobs), poor management and lack of disciplinary action.

- The alienation perspective indicates that an absence of creativity, diversity and independent decision making in work roles can lead to feelings of helplessness and alienation, which in turn may lead to alcohol abuse.

- The work stress perspective focuses on the relationship between stress at work and alcohol use. Stressors can be the work environment, contents of work, role conflict, boredom, inadequate remuneration and the complexity of the work.

According to Trice and Sonnenstuhl (1990), these factors are contributing factors and not necessarily causes of alcohol abuse. There is an interaction between workplace, family, personal, genetic and community factors.

Albertyn and McCann (1993) emphasise the important role of cultural factors in the workplace: "The drinking population seems to move in unison up and down the consumption continuum when changes in culture occur. Individual drinking habits are closely related to drinking habits among friends in the social network. Individual drinking habits and heavy drinking in particular are products of a company's culture. Problem drinking is a learned behavioural disorder and education on its own is useless; it has to be linked to a change in culture" (Albertyn \& McCann, 1993:41). Similarly MacDonald, Wells and Wild (1999) found that a subculture of alcohol abuse was the strongest factor to predict alcohol use by workers.

Ames (1993) maintains that an effective prevention programme should be based on research. Knowledge about risk factors and drinking patterns are indispensable. The following steps are proposed for the development of a prevention programme:

- Initiate research to determine the cost of alcohol abuse to the company (absenteeism, injuries, and disciplinary actions);

- Do research to identify risk factors in the workplace that contribute to alcohol abuse;

- Share the results of the research with management, employees and the human resources section;

- Develop partnerships with other stakeholders, e.g. the EAP programme personnel and health clinics;

- Introduce changes that eliminate or reduce risk factors. 
Ames (1993) warns that it is often difficult to introduce the necessary changes in the workplace and that resistance is common. Strydom (1997) described a similar design for the primary prevention of alcohol abuse in the workplace in a South African industry. Holder (1990 and 1998) advocated a systems approach to the prevention of alcohol problems in the workplace. As there are many similarities between the systems approach and the ecological approach the systems approach is incorporated with the ecological approach in this study. Holder is interested in the total system to which the worker belongs, including cultural and social groups within and outside the workplace, the values and norms of these groups regarding alcohol use, patterns of alcohol consumption, and the role of the family as well as the physical and social availability of alcohol in the workplace. According to Holder, the workplace is an important subsystem of the community and influences the community, as well as being influenced by the community.

\section{EXAMPLES OF PROGRAMMES THAT FOLLOW AN ECOLOGICAL APPROACH}

The Minnesota Mining and Manufacturing company developed a programme for the primary prevention of alcohol abuse in the workplace that can serve as an example of a programme with an ecological approach (Stoltzfus \& Benson, 1994). The programme originated from the traditional approach, but introduced new concepts such as the changing of the culture of the organisation, a consideration of values, attitudes and skills, and a peer-group helping programme. Methods used were still mostly educational in nature e.g. a 10-hour supervisor training programme, a 2.5-hour employee training session and a peer-group training programme. However, the programme also encouraged discussions and joint responsibility for an alcohol-free workplace.

The programme was implemented at one of the branches of the company, while another branch served as a control. Pre- and post-test questionnaires were administered. In the experimental group there was a decrease in alcohol use, an increase in prevention skills, an increase in the acceptance of responsibility for prevention, and a decrease in the effect of alcohol abuse on productivity. A five percent change in the desired direction was accepted as representing meaningful change.

Lehman, Reynolds and Bennett (2002) described a prevention programme that focused on work groups. The aim of the programme was to create awareness that substance abuse was a problem of the group and not only of the individual. Additional aims were to decrease the tolerance of alcohol abuse, to decrease enabling behaviour, to increase the groups' actions towards abuse, improve attitudes towards the substance abuse policy and increase referrals to EAPs.

The work group training consisted of two four-hour sessions. Between nine and fifteen employees took part in each group. Contents of the sessions covered the importance of understanding the impact of alcohol abuse for the group, a discussion of the substance abuse policy, stress management, the risks of allowing substance abuse in the work group, a drinking culture, referral to the EAP, support of the employee with problems, and confidentiality.

The programme was presented to municipal workers in two cities in the south-western United States; 957 employees took part. Work groups were allocated randomly to an experimental group (work group training) and a control group (traditional training), or a second control group (no training). Questionnaires were completed before the training, two to four weeks after the training and six months after the training.

There was no effect on group perceptions on alcohol abuse or the experience of stress in any of the groups. In both the work groups and the traditional training groups there was an increase of 
knowledge of the policy and the EAP. There were mixed results with regard to drinking norms. According to the authors, the findings showed support for both work-group training and traditional training. It can be concluded that there is support in the literature for an ecological approach, although more studies need to be done to develop this approach.

\section{THE HEALTH PROMOTION APPROACH}

The health promotion approach and the lifeskills approach assume different drinking patterns amongst employees. The drinking patterns may vary from total abstinence to social drinking to problem drinking and ultimately to dependence. As different drinking patterns manifest themselves, there are different aims for treatment outcomes, e.g. abstinence or responsible drinking.

\section{DESCRIPTION OF THE HEALTH PROMOTION APPROACH}

In America there is an increasing emphasis on programmes in the workplace that promote health. However, alcohol abuse prevention does not feature regularly amongst these programmes (Cook \& Youngblood, 1990). Cook and Youngblood provide the following reasons for the incorporation of alcohol abuse prevention programmes in health promotion programmes:

- Alcohol abuse is a health risk;

- The use of alcohol and drugs has an impact on all the issues that are normally addressed by a health promotion programme, e.g. stress management, weight management, physical exercise, healthy eating and spiritual wellness;

- Health promotion programmes usually adopt a positive, approach which can be advantageous for conveying alcohol abuse prevention messages. Alcohol abuse prevention programmes are still stigmatised and incorporating them into lifestyle programmes can serve to overcome the stigmatisation problem;

- Health promotion programmes can reach more employees who are heavy drinkers, but who are not dependent. These employees are normally not reached through traditional programmes.

- Health promotion programmes and alcohol prevention programmes can be reciprocally reinforcing.

There is also resistance to the incorporation of alcohol prevention programmes into health promotion programmes. Presenters of health promotion programmes may choose to focus on the positive and pleasurable aspects of a healthy lifestyle and not on the more complex problems of preventing abuse. Management may be unwilling to address substance abuse. The emphasis on a healthy lifestyle and the prevention of cardiovascular problems may lead to an under-exposure of the alcohol problems.

\section{EXAMPLES OF PROGRAMMES THAT FOLLOW A HEALTH PROMOTION APPROACH}

Cook and Youngblood (1990) quote two studies by Shain in which alcohol abuse prevention and the promotion of a healthy lifestyle were successfully integrated. The "Take Charge" programme extended over six hours and encouraged participants to evaluate their lifestyle with reference to cardiovascular problems, stress and alcohol abuse. Messages on alcohol abuse and its effect on health were integrated in sessions on fitness and stress. Questionnaires were administered before and after the intervention. Heavy drinkers reduced their alcohol intake by 
12.3 units (men) and 9 units (women) of alcohol. Moderate drinkers also reduced their intake. There was no control group in this study. "Beyond Stress" was another programme that focused on the acquisition of social skills and techniques of relaxation. In a quasi-experimental study the author found that male subjects who drank moderately reduced their intake significantly. There was no change in the control group.

Cook and his co-workers developed the health promotion approach further. Cook, Back and Trudeau (1996b) implemented a programme called "SAY YES! Healthy Choices for Feeling Good" at a manufacturing facility in the north-eastern United States. The programme was delivered into three sessions:

- Session 1: Introduction (45 minutes). Concepts of a healthy lifestyle, personal choices and the impact of alcohol and drug use on health and well-being were discussed;

- Session 2: Drugs, alcohol and a healthy lifestyle. (11/2 hour). Investigate the rewards and costs attached to the use of alcohol and drugs in comparison with healthy choices, e.g. relaxation exercises, physical exercise and recreational activities. Guidelines for responsible alcohol use and skills for the refusal of drinks were presented;

- Session 3: Healthy choices into action (45 minutes). Guidelines were given on the process of change, e.g. setting realistic goals and acquiring social support.

The programme was evaluated with an experimental research design. There were positive results for attitude towards healthy behaviour, self-efficacy and the desire to cut down on drinking. There was no impact on alcohol consumption. The authors argued that attitude change precedes behaviour change.

The next programme that the authors developed, "Working People: Decisions about Drinking" (Cook et al., 1996b) focused more strongly on alcohol use and targeted mainly the blue-collar workforce. The programme was implemented at a printing company in Atlanta. Four 30-minute sessions were presented. The sessions are described briefly below:

- Session 1: A Closer look at Drinking - The negative health and lifestyle effects of alcohol abuse were discussed and the idea of "cutting down" was introduced;

- Session 2: Some Important Facts about Alcohol - Information about the properties of alcohol, health risks associated with heavy use, definitions of alcohol use, alcohol dependence and alcohol abuse, and the signs and symptoms of dependence were discussed.

- Session 3: One More Pitcher? - This session focused on decision-making skills and setting personal limits for alcohol use. Refusal skills were taught.

- Session 4: It's about Choices: Building Personal Power - The session focused on healthful alternatives to drinking, e.g. exercise. Additionally, parenting and providing a role model for children were also discussed.

A quasi-experimental pre-test post-test design was used to evaluate the programme. The experimental group showed decreases on two of the three alcohol consumption measures, relative to the comparison group. Positive results were found mostly for the number of drinking days, and not for the amount of alcohol consumed.

In the ongoing development of the programme Cook, Back, Trudeau and McPherson (2002) developed a new model. The authors noticed that where alcohol use played a less prominent role in the health promotion programme, as in the SAY YES! Programme, the interest in the programme was high, but the effect on alcohol use was insignificant. The situation reversed 
where alcohol abuse played a more significant role in the programme content. A programme was thus developed where alcohol use was integrated with the healthy lifestyle material that was presented. The programme was called "Make the Connection" (Cook et al., 2002) and there were three components, namely "The Stress Management Connection", "The Healthy Eating Connection" and "The Active Lifestyle Connection". The aim of the study was to test the effect of the alcohol abuse prevention material, presented during the health promotion programme, on attitudes and behaviour regarding alcohol use. A secondary aim was to determine whether the inclusion of alcohol abuse prevention material had a negative effect on the impact of the health promotion material.

An experimental design was followed in the study. Participants were randomly allocated to the healthy lifestyle (HL) group or a group that incorporated alcohol abuse prevention with the healthy lifestyle material (HL+A). Two studies were done, one with stress management and the other with healthy eating habits. The stress management group convened for three sessions of 45 minutes each. In the experimental group $(\mathrm{HL}+\mathrm{A})$ healthy stress management practices were contrasted with the use of alcohol to relieve stress. The control group (HL) received information on stress management only. The same was done in the study on healthy eating habits.

The authors found little difference between the experimental group (HL+A) and control group (HL) in alcohol use in the first study (stress). Both groups improved their stress management skills and decreased their use of alcohol. In the second study (healthy eating) the experimental group had significantly higher measures on the connection between health and alcohol use construct and were more aware of the dangers of alcohol abuse. There was no effect on alcohol use for the experimental or control group. Both groups improved significantly in their eating habits and weight control.

The study demonstrated that alcohol abuse prevention material can be incorporated into a health promotion programme without any negative consequences for the original programme. It was also evident that alcohol abuse decreased in the stress management groups, even where the material on alcohol abuse was not included. Cook et al. (2002) referred to the work of Snow and Kline (1994, 1995) and concluded that this study was an additional indication that programmes on stress management can have an impact on drinking behaviour.

Heirich and Sieck (2000) found that cardiovascular intervention could be an effective means of addressing alcohol abuse. Two thousand employees were randomly allocated to receive intervention individually or in a group format. Counsellors visited the employees at their work stations and did a health assessment. Employees were very interested in the medical examination, e.g. blood tests and cholesterol tests. Half of the group was followed up after three years. Significant results were found for improved cardiovascular health. Also $43 \%$ of employees who were initially identified as high risk drinkers decreased their alcohol intake to safe limits or stopped drinking. Individual follow-up was more successful than a group approach.

Heirich and Sieck (2002) did a similar study with university employees. Faculties were randomly allocated to an experimental group and control group. The experimental group received health screening and individual follow-up. The control group received no intervention. Fifty percent of employees who were identified as heavy drinkers decreased their intake at follow-up and $25 \%$ of these decreased their intake to safe levels. Of those that were described as potential problem drinkers, $42 \%$ were also drinking at safe levels after the intervention. 
Information about the control groups was not available. Heirich and Sieck (2002) demonstrated that proactive assessment of health risks and individual follow-up showed positive results for the prevention of alcohol abuse.

Richmond, Kehoe, Heather and Wodak (2000) combined health screening and brief intervention for employees who demonstrated heavy alcohol use in a study at the Post Offices in Sydney, Australia. An experimental design was followed. All employees in the experimental group received general health promotion material. Those who were identified as heavy drinkers in the health screening part of the programme received brief intervention for alcohol abuse. Similarly programmes were presented to those employees who were identified with eating problems, smoking or stress. There was no reduction for alcohol use in the organization as a whole. However, women in the experimental group showed a decrease in the number of drinks they take.

The studies described in the health promotion approach demonstrated that health promotion programmes can provide a successful avenue for the presentation of alcohol abuse material.

\section{THE LIFE SKILLS APPROACH}

The life skills approach is championed by Snow and Kline and their co-workers (Kline \& Snow, 1994; Snow \& Kline, 1995; Snow et al., 2002; Snow, Swan, Raghavan, Connell \& Kline, 2003) in particular.

\section{DESCRIPTION OF THE LIFE SKILLS APPROACH}

Important concepts in the life skills approach are those of risk factors and protective factors. Risk factors are individual characteristics and characteristics in the environment that contribute towards psychological problems (e.g. depression) and substance abuse. Exposure to multiple risk factors increases the risk of serious psychological problems. Protective factors enable a person to decrease, change or adapt his/her reaction to risk factors in such a way that the risk factors do not have negative consequences (Snow et al., 2002). Protective factors are particularly important in situations in which it is not possible to alter risk factors directly. In the workplace the research focused on risk factors such as stressors (at work and in the family), individual coping skills and social support. This research is summarised by Snow et al. (2002). Snow et al. (2003) also found that employees who reported higher demands, pressures and role conflicts were significantly more likely to experience symptoms of depression, anxiety and somatic complaints. Active coping styles correlated negatively with symptoms of psychological stress, whereas avoidance coping had a positive correlation. The life skills approach thus postulates that stressors at work and in the family and an avoidance style of problem solving are risk factors for the development of psychological problems and substance abuse. On the other hand, active problem solving and social support are protective factors that can prevent psychological problems and substance abuse.

\section{EXAMPLES OF PROGRAMMES THAT FOLLOW A LIFE SKILLS APPROACH}

Snow and Kline (1995) presented the "Yale Work and Family Stress Project" to 239 female secretarial employees in Connecticut. Participants were randomly assigned to an experimental group (136 employees) and control group (103 employees). All participants completed questionnaires before, after, and at 6 months and 22 months after the intervention. Participants met in small groups of 10 to 12 employees for weekly sessions of $1 \frac{1 / 2}{2}$ hours over 15 weeks. There were three components to the programme. In the first component (10 sessions) the focus was on problem solving, the second component concentrated on re-appraisal techniques (2 
sessions) and in the third component active stress management techniques were taught (3 sessions).

Immediately after the intervention participants in the experimental group reported significantly lower employee role stress, higher social support from work sources, lower psychological symptomatology, fewer depressive symptoms, fewer somatic complaints, less tobacco use, less anxiety and greater use of behavioural coping strategies. At the 6-month follow-up, participants also reported, amongst other benefits, lower alcohol use. At 22 months the only significant programme effect was that participants reported fewer somatic complaints.

In a second study certain refinements were made to the original intervention. Direct attention was paid to changing employees' drinking behaviour and discouraging the use of alcohol for stress management purposes. A second control group was added to exclude the confounding effect of extra attention, time off or information. In this control condition participants met for 8 sessions over 16 weeks and information was given on stress, substance use and resources in the community. The experimental group followed a similar programme as described in the first study, except that an extra session was added to the programme. The participants were 468 employees who worked at three organisations in Connecticut. Several instruments were used to determine programme effects. The post-test sample consisted of $72.6 \%$ of the original sample. Participants in the experimental group reported a greater decrease in stress in their roles as spouses and parents compared to the control groups. The experimental group also made more use of social support as a coping mechanism and less of social withdrawal. Intervention participants reported less alcohol use at post-test, particularly drinkers who were heavier alcohol users.

The results of the two studies provide support for the life skills approach to alcohol prevention in the workplace. In these studies the emphasis was on changing the behaviour of individual employees to increase their resilience through individual coping skills and social support. The authors point out that the approach has limitations and indicate the need for a comprehensive model where organisational factors, community factors and individual factors are integrated. A multi-system approach could improve the effectiveness of programmes, but the barriers to the implementation of multi-level programmes in the workplace have to be taken into account. 


\section{TABLE 1}

SUMMARY OF APPROACHES TO THE PREVENTION OF ALCOHOL ABUSE IN THE WORKPLACE

\begin{tabular}{|c|c|c|c|c|}
\hline APPROACH & TRADITIONAL & ECOLOGICAL & HEALTH PROMOTION & LIFE SKILLS \\
\hline $\begin{array}{l}\text { CAUSAL } \\
\text { FACTORS }\end{array}$ & $\begin{array}{l}\text { Genetic factors. } \\
\text { Alcohol is a disease. } \\
\text { Lack of knowledge. }\end{array}$ & $\begin{array}{l}\text { Environmental factors. } \\
\text { Stress, culture, norms, values of } \\
\text { workplace. } \\
\text { Availability. } \\
\text { A permissive culture. }\end{array}$ & $\begin{array}{l}\text { Awareness of health risks absent. } \\
\text { Lack of motivation to change. } \\
\text { Lack of knowledge about changing behaviour. } \\
\text { Lack of social support. }\end{array}$ & $\begin{array}{l}\text { Problems in work and family. } \\
\text { Stress. } \\
\text { Lack of social support. } \\
\text { Avoidance style of coping. }\end{array}$ \\
\hline PROBLEM & Alcohol dependence. & $\begin{array}{l}\text { Alcohol use that influences work } \\
\text { performance. } \\
\text { Unhealthy drinking patterns }\end{array}$ & Unhealthy drinking patterns. & Unhealthy drinking patterns. \\
\hline $\begin{array}{l}\text { INTER- } \\
\text { VENTION }\end{array}$ & $\begin{array}{l}\text { Early identification } \\
\text { and intervention. } \\
\text { Alcohol policy. } \\
\text { Education. } \\
\text { Testing for substances. }\end{array}$ & $\begin{array}{l}\text { Identify and address risk factors } \\
\text { that lead to abuse. } \\
\text { Change the culture of the } \\
\text { organisation. }\end{array}$ & $\begin{array}{l}\text { Cognitive behaviour change. } \\
\text { Social skills, e.g. stress management. } \\
\text { Educational methods. }\end{array}$ & $\begin{array}{l}\text { Cognitive behaviour change. } \\
\text { Social skills training. }\end{array}$ \\
\hline AIMS & Abstinence. & $\begin{array}{l}\text { Decrease in alcohol use. } \\
\text { Responsible drinking. }\end{array}$ & $\begin{array}{l}\text { Decrease in alcohol use. } \\
\text { Responsible drinking. }\end{array}$ & $\begin{array}{l}\text { Decrease in alcohol use. } \\
\text { Responsible drinking. }\end{array}$ \\
\hline $\begin{array}{l}\text { EVALUA- } \\
\text { TION }\end{array}$ & $\begin{array}{l}\text { Increase in } \\
\text { knowledge. } \\
\text { No effect on alcohol } \\
\text { use. }\end{array}$ & $\begin{array}{l}\text { Decrease in alcohol use. } \\
\text { Decrease in negative effect of } \\
\text { alcohol abuse. }\end{array}$ & $\begin{array}{l}\text { Positive results with regard to attitudes towards } \\
\text { alcohol use, health and intention to drink less. } \\
\text { Decrease in alcohol use. }\end{array}$ & $\begin{array}{l}\text { Decrease in alcohol use and in } \\
\text { negative consequences of alcohol } \\
\text { use in workplace. } \\
\text { Improved social support. } \\
\text { Increase in life skills. }\end{array}$ \\
\hline STUDIES & $\begin{array}{l}\text { Albertyn \& McCann, } \\
1993 \\
\text { Cyster \& McEwan, } \\
1987 \\
\text { McLatchie et al., } 1981 \\
\text { Roman, 1990 } \\
\text { Roman \& Blum, } 1996 \\
\text { Strydom, 1997 } \\
\text { Trice \& Sonnenstuhl, } \\
1990\end{array}$ & $\begin{array}{l}\text { Ames \& Janes, } 1990 \\
\text { Ames, } 1993 \\
\text { Ames, Grube \& Moore, } 1999 \\
\text { Delaney \& Ames, } 1995 \\
\text { Holder, 1990 } \\
\text { Stolzfus \& Benson, } 1994 \\
\text { Trice \& Sonnenstuhl, } 1990 \\
\text { Walsh, Rudd, Biener, \& Mangione, } \\
1993\end{array}$ & $\begin{array}{l}\text { Cook \& Youngblood, } 1990 \\
\text { Cook, Back \& Trudeau, } 1996 \\
\text { Heirich \& Sieck, } 2000 \\
\text { Richard et al., 2000 } \\
\text { Towers, Kischuk, Ylvestre, Peters, \& Bourgault, } \\
1994\end{array}$ & $\begin{array}{l}\text { Brochu \& Souliere, } 1988 \\
\text { Kline \& Snow, } 1994 \\
\text { Snow \& Kline, } 1995 \\
\text { Snow, Swan \& Wilton, } 2002 \\
\text { Snow et al., 2003. }\end{array}$ \\
\hline
\end{tabular}

Social Work/Maatskaplike Werk 2011:47(1) 


\section{DISCUSSION}

From this summary of approaches to the prevention of alcohol abuse in the workplace, it is evident that there are promising developments in the field of substance abuse prevention. Positive results were obtained in studies based on the ecological approach, the health promotion approach and the life skills approach. It is evident that the literature supports the ecological and cognitive behavioural approaches (both the health promotion approach and the life skills approach utilise cognitive behavioural methods). According to Cook (2002), the cognitive behavioural approach has also been found to be the most successful in the treatment of substance dependence (e.g. minimal intervention therapies, motivational interviewing and selfregulation). It is thus not surprising that cognitive behavioural methods also show promise in the prevention of alcohol abuse.

However, alcohol abuse is a multi-factorial problem and several authors (Cook et al., 1996a; Snow \& Kline, 1995) point out that substance abuse should be addressed on different levels, e.g. individual, organisational, family and community levels. The question of which approach to follow thus remains. While a multi-level approach might seem more beneficial, it is not easy to gain access to a workplace and a multi-level approach might place heavy demands on management in terms of money and time. Management support and workplace politics play a crucial role in the success of a prevention programme. It is the view of the author that the approach should be determined by evidence of success from the literature, the characteristics of the target group for whom the programme is intended, and the practicalities and demands of the workplace situation.

\section{CONCLUSION}

This article summarises the most important approaches to the prevention of alcohol abuse in the workplace. It is evident that programmes that are solely focused on the increase of knowledge have not demonstrated much success. On the other hand, there is support for programmes based on an ecological and a cognitive behavioural approach. Programme planners can increase the validity of their programmes by ensuring that prevention programmes have a programme theory based on an approach to prevention for which there is evidence in the literature.

\section{REFERENCES}

ALBERTYN, C. \& McCANN, M. 1993. Alcohol, employment and fair labour practice. Cape Town: Juta and Co. Ltd.

AMES, G. 1993. Research and strategies for the primary prevention of workplace alcohol problems. Alcohol, Health and Research World, 17(1):19-27.

AMES, G.M. \& GRUBE, J.W. 1999. Alcohol availability and workplace drinking: mixed method analyses. Journal of Studies on Alcohol, 60:383-393.

AMES, G.M., GRUBE, J.W. \& MOORE, R.S. 1997. The relationship of drinking and hangovers to workplace problems: An empirical study. Journal of Studies on Alcohol, 58(1):37-47.

AMES, G. \& JANES, C. 1990. Drinking, social networks and the workplace: results of an environmentally focused study. In: ROMAN, P. (ed) 1990. Alcohol problem intervention in the workplace. Westport, CT: Quorum Books.

CHEN, H. 1990. Theory-driven evaluations. California: Sage Publications. 
COOK, R.F. \& YOUNGBLOOD, A. 1990. Preventing substance abuse as an integral part of worksite health promotion. Occupational Medicine, 5(4):725-738.

COOK, R.F., BACK, A. \& TRUDEAU, J. 1996a. Substance abuse prevention in the workplace: recent findings and an expanded conceptual model. The Journal of Primary Prevention, 16(3):319-339.

COOK, R.F., BACK, A. \& TRUDEAU, J. 1996b. Preventing alcohol use problems among blue-collar workers: a field test of the Working People Program. Substance Use and Misuse, 31(3):255-275.

COOK, R.F., BACK, A.S., TRUDEAU, J. \& McPHERSON, T. 2002. Integrating substance abuse prevention into health promotion programs in the workplace: A social cognitive intervention targeting the mainstream user. In: BENNETT, J.B. \& LEHMAN, W.E.K. (eds) Preventing workplace substance abuse. Beyond drug testing to wellness. Washington, DC: American Psychological Association.

CYSTER, R. \& McEWAN, J. 1987. Alcohol education in the workplace. Health Education Journal, 46(4):156-161.

DELANEY, W.P. \& AMES, G. 1995. Work team attitudes, drinking norms, and workplace drinking. The Journal of Drug Issues, 25:275-290.

GILL, J. 1994. Alcohol problems in employment: epidemiology and responses. Alcohol and Alcoholism, 29(3):233-248.

HEIRICH, M. \& SIECK, C.J. 2000. Worksite cardiovascular wellness programs as a route to substance abuse prevention. Journal of Occupational and Environmental Medicine, 42(1):47-56.

HOLDER, H.D. 1990. Prevention of alcohol problems in the workplace: a public policy perspective. In: ROMAN, P. Alcohol problem intervention in the workplace. Westport, CT: Quorum Books.

HOLDER, H.D. 1998. Planning for alcohol-problem prevention through complex systems modeling: results from SimCom. Substance Use and Misuse, 33(3):669-692.

KLINE, M.L. \& SNOW, D.L. 1994. Effects of a worksite coping skills intervention on the stress, social support, and health outcomes of working mothers. The Journal of Primary Prevention, 15(2):105-121.

LEHMAN, W.E.K., REYNOLDS, G.S. \& BENNETT, J.B. 2002. Team and informational trainings for workplace substance abuse prevention. In: BENNETT, J.B. \& LEHMAN, W.E.K. (eds) 2002. Preventing workplace substance abuse: beyond drug testing to wellness. Washington, DC: American Psychological Association.

MacDONALD, S., WELLS, S. \& WILD, T.C. 1999. Occupational risk factors associated with alcohol and drug problems. The American Journal of Drug and Alcohol Abuse, (2):351-369.

McLATCHIE, B.H., GREY, P.M., JOHNS, Y. \& LOMP, K.G.E. 1981. A component analysis of an alcohol and drug program: employee education. Journal of Occupational Medicine, 23(7):477-480.

MOSKOWITZ, J.M. 1989. The primary prevention of alcohol problems: a critical review of the literature. Journal of Studies on Alcohol, 50(1):54-88. 
PARRY, C.D.H. \& BENNETTS, A.L. 1998. Alcohol policy and public health in South Africa. Cape Town: Oxford University Press.

PENTZ, M. 1999. Prevention. In: GALANTER, M. \& KLEBER, H.D. 1999. Textbook of substance abuse treatment $\left(2^{\text {nd }}\right.$ ed). Washington, DC: American Psychiatric Press, Inc.

RICHMOND, R., KEHOE, L., HEATHER, N. \& WODAK, A. 2000. Evaluation of a workplace brief intervention for excessive alcohol consumption: the workscreen project. Preventive Medicine, 30(1):51-63.

ROMAN, P. 1990. Alcohol problem intervention in the workplace. Westport, CT: Quorum Books.

ROMAN, P. \& BLUM, T.C. 1996. Alcohol: a review of the impact of worksite interventions on health and behavioral outcomes. American Journal of Health Promotion, 11(2):137-149.

ROMAN, P. \& BLUM, T.C. 2002. The workplace and alcohol problem prevention. Alcohol Research and Health, 26(1):49-57.

SEEMAN, M., SEEMAN, A.Z. \& BUDROS, A. 1988. Powerlessness, work, and community: A longitudinal study of alienation and alcohol use. Journal of health and social behavior, 29:185-198.

SNOW, D.L. \& KLINE, M.L. 1995. Preventive interventions in the workplace to reduce negative psychiatric consequences of work and family stress. In: MAZURE, C.M. Does stress cause psychiatric illness? Washington: American Psychiatric Press, Inc.

SNOW, D.L., SWAN, S.C. \& WILTON, L. 2002. A workplace coping skills intervention to prevent alcohol abuse. In: BENNETT, J.B. \& LEHMAN, W.E.K. (eds) 2002. Preventing workplace substance abuse: beyond drug testing to wellness. Washington, DC: American Psychological Association.

SNOW, D.L., SWAN, S.C., RAGHAVAN, C., CONNELL, C.M. \& KLINE, I. 2003. The relationship of work stressors, coping and social support to psychological symptoms among female secretarial employees. Work \& Stress, 17(3):241-263.

SOUTH AFRICA. DEPARTMENT OF SOCIAL DEVELOPMENT. 2007. National Drug Master plan: 2006-2011.

STOLTZFUS, J.A. \& BENSON, P.L. 1994. The 3M alcohol and other drug prevention program: description and evaluation. The Journal of Primary Prevention, 15(2):147-159.

STRYDOM, A.M.M. 1997. Die ontwikkeling van 'n voorkomingsprogram vir alkoholmisbruik in die mynbedryf. Bloemfontein: UOVS. (PhD proefskrif)

TOWERS, A.M., KISCHUK, N., SYlVESTRE, M., PETERS, C. \& BOURGAULT, C. 1994. A qualitative investigation of organizational issues in an alcohol awareness program for bluecollar workers. American Journal of Health Promotion, 9(1):56-63.

TRICE, H.M. 1990. Implications for intervention and prevention in three streams of EAPrelated research. In: ROMAN, P. Alcohol problem intervention in the workplace. Westport: CT: Quorum Books.

TRICE, H.M. \& SONNENSTUHL, W.J. 1990. On the construction of drinking norms in work organizations. Journal of Studies on Alcohol, 51(3):201-220. 
WALSH, D.C., RUDD, R.E., BIENER, L. \& MANGIONE, T. 1993. Researching and preventing alcohol problems at work: toward an integrative model. American Journal of Health Promotion, 7(4):289-295.

Dr Wilhelmina Steenkamp, Social Worker, Department of Social Work, Tygerberg Hospital, Tygerberg, South Africa. 